\title{
V-ATPase upregulation during early pregnancy: a possible link to establishment of an inflammatory response during preimplantation period of pregnancy
}

\author{
Mukesh K Jaiswal, Timothy M Mallers, Benjamin Larsen, Joanne Kwak-Kim, Gerard Chaouat ${ }^{1}$, \\ Alice Gilman-Sachs and Kenneth D Beaman
}

Department of Microbiology and Immunology, Rosalind Franklin University of Medicine and Science, 3333 Green Bay Road, North Chicago, Illinois 60064, USA and ${ }^{1}$ U 782 INSERM, Université Paris Sud, and Hópital Antoine Béclére, Clamart 92141, France

Correspondence should be addressed to K D Beaman; Email: kenneth.beaman@rosalindfranklin.edu

\begin{abstract}
Various mechanisms exist to prevent a potentially deleterious maternal immune response that results in compromising survival of semiallogeneic fetus. In pregnancy, there is a necessary early preimplantation inflammatory stage followed by a postimplantation antiinflammatory stage. Thus, there is a biphasic 'immune response' observed during the course of pregnancy. We provide the evidence that capacitation of sperm induced the expression of a2 isoform of V-ATPase (ATP6V0A2 referred to as a2V), leukemia inhibitory factor (Lif), $I I 1 b$, and Tnf in the sperm. Capacitated sperm also released cleaved N-terminal domain of a2V-ATPase (a2NTD), which upregulates the gene expression of Lif, II1 b, Tnf, and monocyte chemotactic protein-1 (Ccl2 (Mcp1)) in the uterus. Unfertilized eggs had low a2V expression, but after fertilization, the expression of $\mathrm{a} 2 \mathrm{~V}$ increased in zygotes. This increased level of a2V expression was maintained in preimplantation embryos. Seminal plasma was necessary for upregulation of a2V expression in preimplantation embryos, as mating with seminal vesicle-deficient males failed to elicit an increase in a2 $\mathrm{V}$ expression in preimplantation embryos. The infiltration of macrophages into the uterus was significantly increased after insemination of both sperm and seminal plasma during the preimplantation period of pregnancy. This dynamic infiltration into the uterus corresponded with the uterine a2V expression through the induction of $C c / 2$ expression. Furthermore, the polarization ratio of M1:M2 (pro-inflammatory/anti-inflammatory) macrophages in the uterus fluctuated from a ratio of 1.60 (day 1 ) to 1.45 (day 4 ) when female mice were inseminated with both sperm and seminal plasma. These data provide evidence that exposure to semen may initiate an inflammatory milieu by inducing a2V and cytokine/chemokine expression, which triggers the influx of macrophages into the preimplantation uterus during the onset of pregnancy and ultimately leads to successful pregnancy outcome.
\end{abstract}

Reproduction (2012) 143 713-725

\section{Introduction}

Sperm capacitation is the final step of sperm maturation. This phenomenon occurs in the reproductive tract of the female for a finite period before the sperm can fertilize the egg (Austin 1951, Chang 1951). During capacitation, sperm undergo several physiological changes that start with ejaculation. Several other changes arise over a longer period in the female tract. However, a very early event in sperm capacitation is the activation of sperm motility. In vivo immotile sperm are stored in the cauda epididymis and the vigorous movement of flagellum starts when sperm are released from the epididymis and come into contact with the high concentration of $\mathrm{HCO}_{3}^{-}$ and $\mathrm{Ca}^{++}$present in the seminal fluid. Capacitation may be induced in vitro in appropriate media (Visconti 2009). In vitro capacitation media contains a protein source, usually BSA, and ions including $\mathrm{HCO}_{3}^{-}$and $\mathrm{Ca}^{++}$. Previously, it was reported that during sperm capacitation, BSA acts as a sink for the depletion of cholesterol from sperm plasma membrane and that $\mathrm{HCO}_{3}^{-}$and $\mathrm{Ca}^{++}$ions stimulate protein tyrosine phosphorylation through cAMP. Finally, through this increase in protein tyrosine phosphorylation, sperm acquire fertilizing capacity (Salicioni et al. 2007). Several studies on rodent, livestock species, and humans suggest that the introduction of ejaculated sperm into the maternal reproductive tract stimulates several molecular and cellular changes, with physiological consequences bearing on conception and pregnancy (Robertson 2007). Factors associated with sperm and seminal fluid have potential biological effects in the mother, which includes cytokines, sex hormones, and prostaglandins (Aumuller \& Riva 1992, Maegawa et al. 2002). 
These molecules target the cells of the cervix, uterus, and oviduct and induce early inflammatory responses important for the establishment of successful implantation (Manjunath et al. 1994, Robertson et al. 2006).

In addition to DNA, sperm contribute RNA and proteins to the ova, which are crucial for early embryonic development (Ainsworth 2005). We tested mouse sperm for the presence of an important immune regulatory molecule a2 $\mathrm{V}$ and studied its possible immune-regulatory role during capacitation and early embryonic development. Earlier studies demonstrated that $\mathrm{a} 2 \mathrm{~V}$ is one of the first molecules expressed in pregnancy that has regulatory effects on the maternal immune response (Lee et al. 2001). Sun-Wada et al. (2002) have previously reported that a2V was expressed in mature sperm. Skinner et al. (1999) showed that expression of V-ATPase subunits in the bovine endometrium was crucial for trophoblast invasion and cellular communication during the window of implantation. Additionally, the acidic environment regulated by V-ATPase is important for the development of the preimplantation embryo following implantation (Sun-Wada et al. 2000). Our recent studies have shown that a2 $\mathrm{V}$ affects cytokine and chemokine expression and may be a key factor in the early control of the inflammatory process necessary for implantation and placentation (Ntrivalas et al. 2010, Jaiswal et al. 2011). Several inflammatory cytokines are known to be important in implantation (Chaouat et al. 2007). Leukemia inhibitory factor (LIF) is known to be mandatory for implantation in mice (Stewart et al. 1992, Aghajanova 2010). It is expressed in the endometrium maximally during the implantation period; the LIF receptor is localized in villous and extravillous trophoblasts. LIF is involved in mediating interactions between maternal decidual leukocytes and trophoblasts. LIF enhances HLA-G expression in trophoblasts and supports the establishment of maternal immune tolerance at the feto-maternal interface (Jones et al. 1997). Hoxa10 gene is a leading candidate for regulating differentiation of the uterine endometrium in the preparation for blastocyst implantation (McGinnis \& Krumlauf 1992, Krumlauf 1994). The uteri of Hoxa10deficient mice are not supportive of implantation (Satokata et al. 1995, Taylor et al. 1997).

Previously, we have shown that a2V can regulate IL1B as well as IL1A with little or no subsequent increase in TNF secretion (Ntrivalas et al. 2007, Kwong et al. 2011). This process appears to occur by two different mechanisms. The first is a2 $\mathrm{V}$ expression on the cell surface, where it functions as an ATPase preventing the danger-associated molecular pattern (DAMP) ATP from activating the inflammasome through the $\mathrm{P} 2 \mathrm{X} 7$ channel (Ntrivalas et al. 2007). ATP binding to P2X7 causes the influx of potassium ions and the activation of the inflammasome (Kwong et al. 2011). The second mechanism is the cleavage and release of soluble
$\mathrm{N}$-terminus portion (a2NTD) from a2V. This a2NTD peptide is responsible for the selective increase in transcription and secretion of several different cytokines and chemokines important in maintaining specific immune responses (Ntrivalas et al. 2010, Kwong et al. 2011).

One of the key events mediated by chemokines and cytokines is the regulation of migration of specific mononuclear cells to the uterus during pregnancy (Hunt \& Pollard 1992, Hunt et al. 2000, Mor \& Koga 2008). Macrophages and NK cells infiltrate as the most prominent leukocyte populations in the uterine tissues during the first trimester of pregnancy (Gomez-Lopez et al. 2010). These cells are important modulators of vascular remodeling and immune activity in the uterus and developing placenta (Hunt et al. 1985, Moffett-King 2002, Tabiasco et al. 2006). Recently, two distinct subsets of macrophages have been defined. Type 1 or M1 macrophages have the traditional characteristics of cytotoxicity and the release of inflammatory cytokines and chemokines. Type 2 or M2 macrophages are found associated with tumors and tumor angiogenesis (Mantovani et al. 2002, Gordon 2003, Mosser 2003). M2 macrophages are associated with the resolution of inflammation and also with angiogenesis (Mantovani et al. 2002).

Previously, we have shown that a2V regulates a delicate network of cytokines and chemokines that coordinates the recruitment of M1 and M2 macrophages to the feto-maternal interface for successful placental development and growth (Jaiswal et al. 2011). In this study, we correlated the pattern of cytokine and chemokine expression with macrophage movement into the uterus during implantation and show that macrophages migrate in an order of the reflective events induced by the upregulation of uterine $\mathrm{a} 2 \mathrm{~V}$ expression and monocyte chemotactic protein-1 (Mcp1) upon female exposure to sperm accompanied with seminal plasma. We conclude that capacitation induces a2V, Lif, ILIb, and Tnf expression in the sperm. Capacitation also brings the release of a2NTD that, in turn, induces maternal inflammatory cytokines such as Lif, II1 b, Tnf, and CCl2 (Mcp1) expression. The exposure of the uterus with sperm accompanied by seminal plasma induces the accumulation of macrophages before blastocyst implantation on day 4 of pregnancy through upregulation of a2V and $\mathrm{CCl} 2$.

\section{Results}

\section{Sperm capacitation induces a2V and cytokine expression}

We first looked for a2 $\mathrm{V}$ expression in sperm collected from the cauda epididymis. a2V was not detected in sperm before capacitation (Fig. 1). However, the 
$\underline{\mathrm{a} 2 \mathrm{~V} \text { expression in capacitated sperm }}$
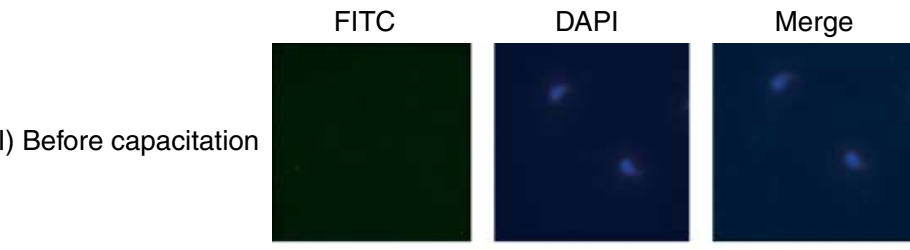

(II) Noncapacitated sperm
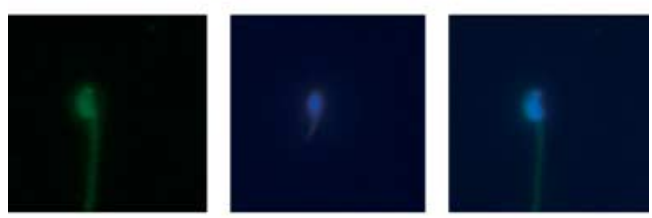

(III) Capacitated sperm

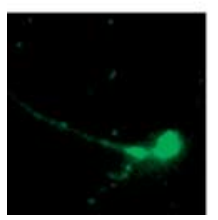

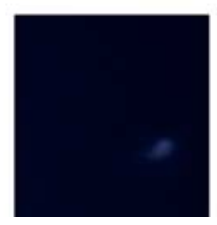

Figure 1 Capacitation of sperm induces a2V expression in sperm. A, The photomicrograph shows immunolocalization of a2V in sperm recovered from epididymis. Green (FITC) shows localization of a2 $\mathrm{V}$ and blue (DAPI) shows nuclear stain. Panel I shows that no expression occurs before capacitation. Panel II shows lower expression of a2V in noncapacitated sperm recovered from KR without calcium and BSA. Panel III shows higher expression of a2V in capacitated sperm recovered from KR with calcium and BSA. Data are representative of five experiments. expression of a2V was increased after incubation with capacitation buffer (KR buffer with calcium and BSA). After 90 min incubation with capacitation buffer, a2V was abundantly detected in the sperm (Fig. 1). Real-time PCR studies confirmed that the gene expression of a2 $v$, Lif, II1b, and Tnf was significantly higher in the sperm recovered after 90 min incubation with capacitation buffer when compared with their respective controls (Fig. 2A, B, C and D). The I/10 gene expression was not detected in the capacitated sperm. This finding suggests that capacitation induces a2V and Lif, $I / 1 b$, and Tnf cytokine expression in sperm.

\section{a2NTD induces inflammatory cytokine expression in the prepared uterus}

The a2NTD peptide was detected in the supernatants recovered after sperm capacitation (Supplementary Figure S2, see section on supplementary data given at the end of this article). In order to prove that a2 $\mathrm{V}$ expression directly led to cytokine expression in vivo, recombinant a2NTD was injected into the uterus during proestrous stages of females and different cytokine expression was measured. As shown in Fig. 3, only the uterine horn that was injected with a2NTD showed significantly higher expression of Lif, I/1b, Tnf, and CCl2. However, this was not seen in the a2NTD-injected uterine horn of randomly selected female mice that were not in the proestrous stage, where the cytokine expression was almost undetectable (Supplementary Table S1, see section on supplementary data given at the end of this article). These data indicate that a2NTD interacts with uterine epithelium of the prepared uterus and induces the expression of Lif, II1 b, Tnf, and CCl2 in vivo (Fig. $3 \mathrm{~A}, \mathrm{~B}, \mathrm{C}$ and $\mathrm{D}$ ).

\section{Expression of a2 $\mathrm{V}$ in the preimplantation embryos recovered from intact or seminal plasma-deficient matings}

Immunocytochemistry studies showed that a very low level of a2 $\mathrm{V}$ expression was observed in the mature ova recovered from female mice (Fig. 4). However, a2V expression was significantly increased after fertilization in the preimplantation embryos recovered from intact (INT) mating as shown in Fig. 4. The zygote and two-cell stage embryos were highly positive for a2 $\mathrm{V}$ and had a distinct peripheral expression pattern. The staining of a2 $\mathrm{V}$ was brightest in the morula and blastocyst recovered from INT mating. However, in seminal plasma-deficient (SVX) mating, very low expression of a2 $\mathrm{V}$ was seen at different stages of the preimplantation embryo. However, expression of a2 $\mathrm{V}$ was decreased in the implanted blastocyst recovered from both the groups (Fig. 4). This differential expression of $\mathrm{a} 2 \mathrm{~V}$ in preimplantation embryos recovered from the INT or SVX mating clearly suggests that a2 $\mathrm{V}$ expression is the result of the presence of seminal plasma. These data showed that the exposure to both sperm and seminal plasma in INT mating contributes to increased expression of $\mathrm{a} 2 \mathrm{~V}$ in preimplantation embryos.

The expression of a2vand Lif mRNA was measured by real-time PCR in preimplantation embryos recovered from mating. As shown in Supplementary Figure S1, see section on supplementary data given at the end of this article, Lif was not detectable in the zygote (day 1 ) and two-cell stage embryos (day 2), whereas a2 $v$ gene expression was found in zygotes and increased in twocell embryos. However, on day 4, a $2 v$ expression decreased and Lif expression increased dramatically in blastocyst. After implantation on day 6, the expression of both $a 2 v$ and $L$ if was not detected in implanted embryos. 

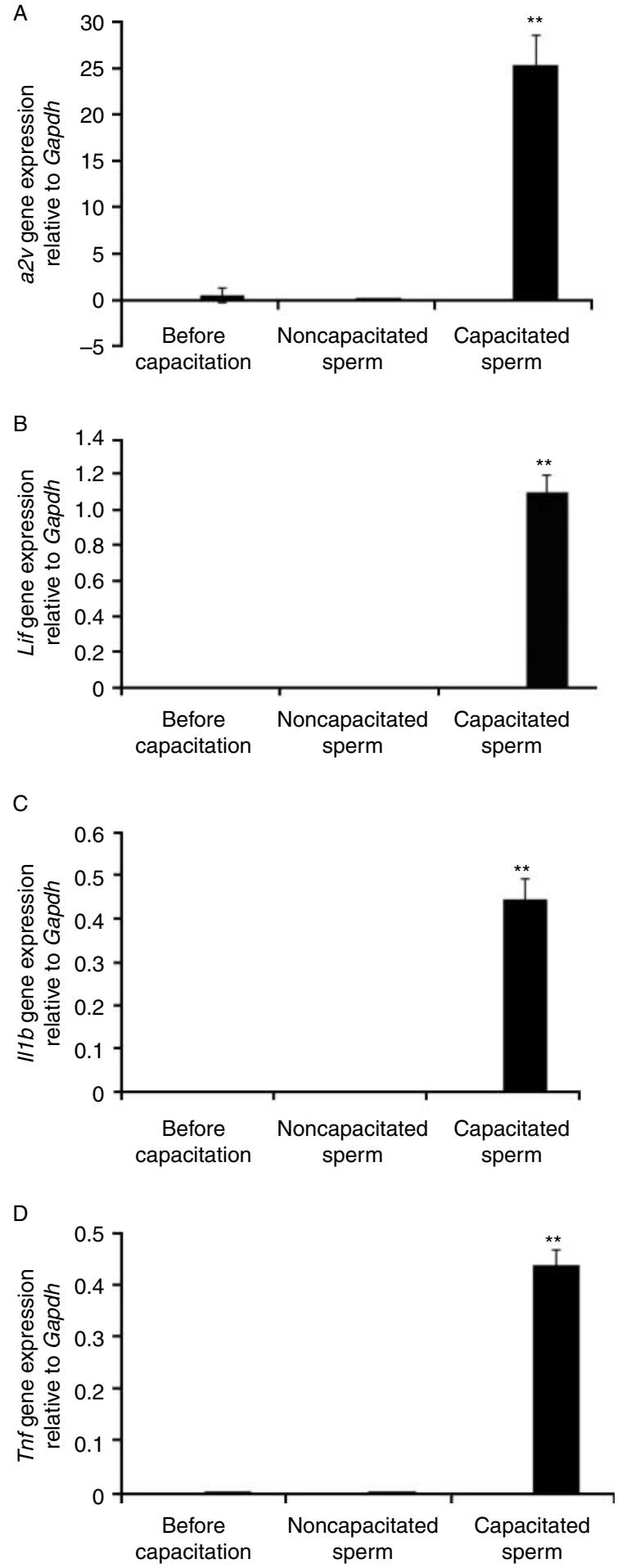

Figure 2 Capacitation of sperm induces the gene expression of a $2 v$ and different cytokines. Gene expression of (A) a2V, (B) Lif, (C), I/1 b, and (D) Tnf in sperm recovered from after 90 min incubation at $37^{\circ} \mathrm{C}$ in $5 \%$ $\mathrm{CO}_{2}$ in KR buffer with or without calcium and BSA. a2V, Lif, II1 b, and Tnf gene expression was significant higher in the capacitated sperm recovered from KR with calcium and BSA when compared with sperm recovered before capacitation or from KR buffer without calcium and BSA. Data are from five independent experiments (mean \pm S.E.M.). **Significant difference vs respective control, $P<0.01$.
Lif expression remained undetectable, but a low level of a2 $v$ expression was observed in the embryos recovered on day 8 of pregnancy (Supplementary Figure S1).

\section{Expression of a2V, Ccl2, Lif, and Hoxa10 in the uterus recovered from intact, seminal plasma-deficient, and vasectomized matings}

The real-time PCR studies showed that the levels of gene expression of $\mathrm{a} 2 \mathrm{v}, \mathrm{CCl} 2$, and Lif were significantly increased from days 1 (time period after few hours of insemination) to 4 in the uterus recovered from the INT mating when compared with seminal plasma-deficient (SVX) or vasectomized (VAS) matings (Fig. 5A, B and C). The increased gene expression of a $2 v$ on day 4 in the uterus of the intact mating corresponds with the increased gene expression of $\mathrm{CCl} 2$ and Lif (Fig. 5A, B and C). Hoxa10 gene expression was similar in all studied groups on day 1, but its expression was significantly decreased in the SVX or VAS matings on day 4 when compared with the INT mating (Fig. 5D). By immunohistochemistry, we examined the localization of $\mathrm{a} 2 \mathrm{~V}$ in the uterus during preimplantation period of pregnancy. Immunohistological staining in the uterus showed that the density of a2 $\mathrm{V}$ expression followed the same pattern as its gene expression (Fig. 6). On day 1, a2 $\mathrm{V}$ protein primarily localized to the stromal cells of the uterus (Fig. 6A). Its density of expression was significantly increased near the window of implantation on day 4 uterus recovered from intact mating (ISIS $=5.67$ \pm 0.86 , day $1 ;$ ISIS $=13.45 \pm 1.25$, day 4) (Fig. $6 \mathrm{D}$ and G). On day 4, a2V protein was localized to the glandular and luminal epithelium as well as stromal cells in the uterus. However, in SVX or VAS matings, the a2V expression was not increased near the window of implantation on day 4 (ISIS $=04.98 \pm 1.89$, SVX; $05.22 \pm 1.14$, VAS) (Fig. 6E, F, H and I). These data demonstrate that the expression of a2V, Ccl2, and Lif was significantly upregulated in the uterine horn, which was exposed to sperm accompanied with seminal plasma (INT mating), as their expression was not increased when females were mated with SVX or VAS males. Moreover, for the consistent gene expression of Hoxa10, the exposure of both sperm and seminal plasma to the uterus is crucial, as its expression was deceased in uterus recovered from SVX or VAS matings.

\section{Infiltration of M1 and M2 macrophages in the uterus recovered from intact, seminal plasma-deficient, and VAS matings}

CCl2 is well known to amplify the recruitment of macrophages and other immune effector cells into reproductive tissues (Critchley et al. 1996, Jones et al. 1997). By immunohistochemistry, we examined the infiltration and polarization of M1 (ITGAX) (Fig. 7) and M2 (MRC1) (Fig. 8) macrophages in the uterus recovered 

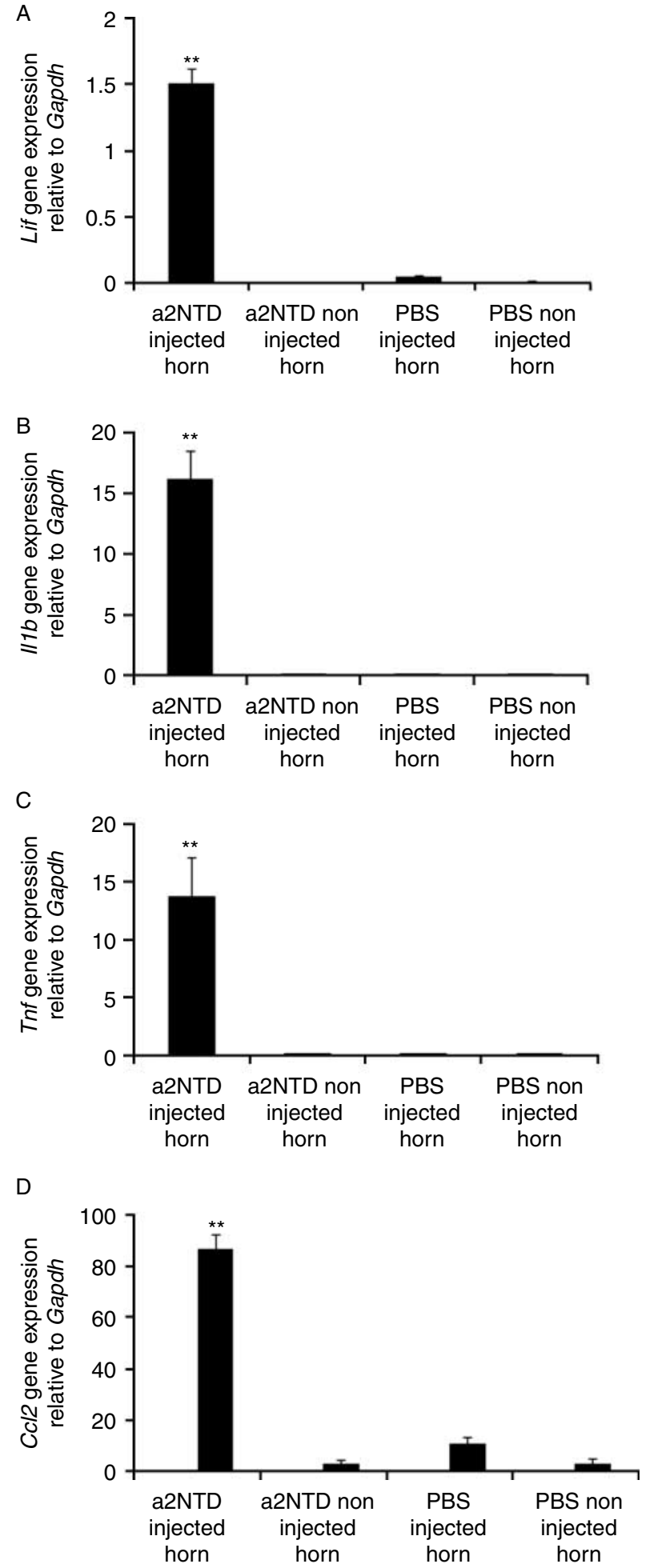

Figure 3 a2NTD induces cytokine expression in uterus. The bar diagrams show the gene expression of (A) Lif, (B) I/1 b, (C) Tnf, and (D) $\mathrm{CCl} 2$ in uterine horn recovered from control and $10 \mathrm{ng}$ intrauterine a2NTD-injected BALB/C females. Lif, I/1 b, Tnf, and Ccl2 gene expression was higher in the a2NTD-injected horn than their respective controls. Data are from four independent experiments (mean \pm s.E.M.). **Significant difference vs respective control, $P<0.01$. during the preimplantation period of pregnancy. The number of $M 1$ and $M 2$ macrophages was significantly $(P \leq 0.05)$ higher in the uterus recovered from INT mating when compared with the SVX or VAS matings on both day 1 (time period after few hours of insemination) and day 4 (near the window of implantation) (Figs 7 and 8). There was significantly higher expression of a2 $\mathrm{V}$ in the day 4 uterus of the INT mating, which corresponds to a significantly higher level of $\mathrm{Ccl} 2$ expression as well as increased infiltration of $\mathrm{M} 1$ and $\mathrm{M} 2$ macrophages when compared with the SVX or VAS matings. The levels of infiltration of $\mathrm{M} 1$ and $\mathrm{M} 2$ macrophages directly correlated with the expression of $\mathrm{Ccl} 2$, which corresponded to the expression of a2 $\mathrm{V}$ in the uterus during different days of pregnancy. The polarization pattern of macrophages on days 1 and 4 was skewed to the $M 1$ phenotypes $(\mathrm{M} 1 / \mathrm{M} 2=1.6$, day $1 ; 1.45$, day 4$)(\mathrm{Fig} .8 \mathrm{H})$ in the uterus recovered from INT mating. However, this change was not seen in the SVX or VAS matings (Fig. 8H). These data indicate that the higher expression of uterine a2 $\mathrm{V}$ corresponds with the dynamic infiltration of $\mathrm{M} 1$ and M2 macrophages through the induction of $\mathrm{CCl} 2$ expression. This strengthens the hypothesis that a2V regulates the delicate cytokine and chemokine networks and coordinates the recruitment of macrophages important in successful implantation.

\section{Discussion}

We report for the first time that sperm capacitation induces the expression of the immune regulatory molecule a2 $\mathrm{V}$ and the cytokines Lif, $I / 1 \mathrm{~b}$, and Tnf in sperm. It is a well-known fact that capacitation is the final stage of sperm maturation (Austin 1951, Chang 1951). Our data now provide clear evidence that capacitation of sperm is not only a step of maturation but also induces the cytokines necessary for the onset of pregnancy. The role of maternal immune responses to the developing embryo has been intensely studied. It is known that various mechanisms exist to prevent a potentially deleterious maternal immune response, which, would result in compromising the survival of the semiallogeneic fetus (Chaouat et al. 2010). However, it is also known that several inflammatory cytokines, which are potentially harmful to the fetus, are necessary for successful implantation during preimplantation period (Chaouat et al. 2007, 2010). Thus, there is a biphasic 'immune response' required during the course of a successful pregnancy. There is an early inflammatory stage, followed by an anti-inflammatory stage required to prevent the detrimental effect on pregnancy (Mor et al. 2011). We provide evidence that sperm can initiate this unique immune process upon capacitation by inducing both a2V and different cytokines such as Lif, I/1 b, and Tnf expression in the sperm. Thus, it is a paternal factor that initiates an essential inflammatory milieu required for successful implantation. 
A INT

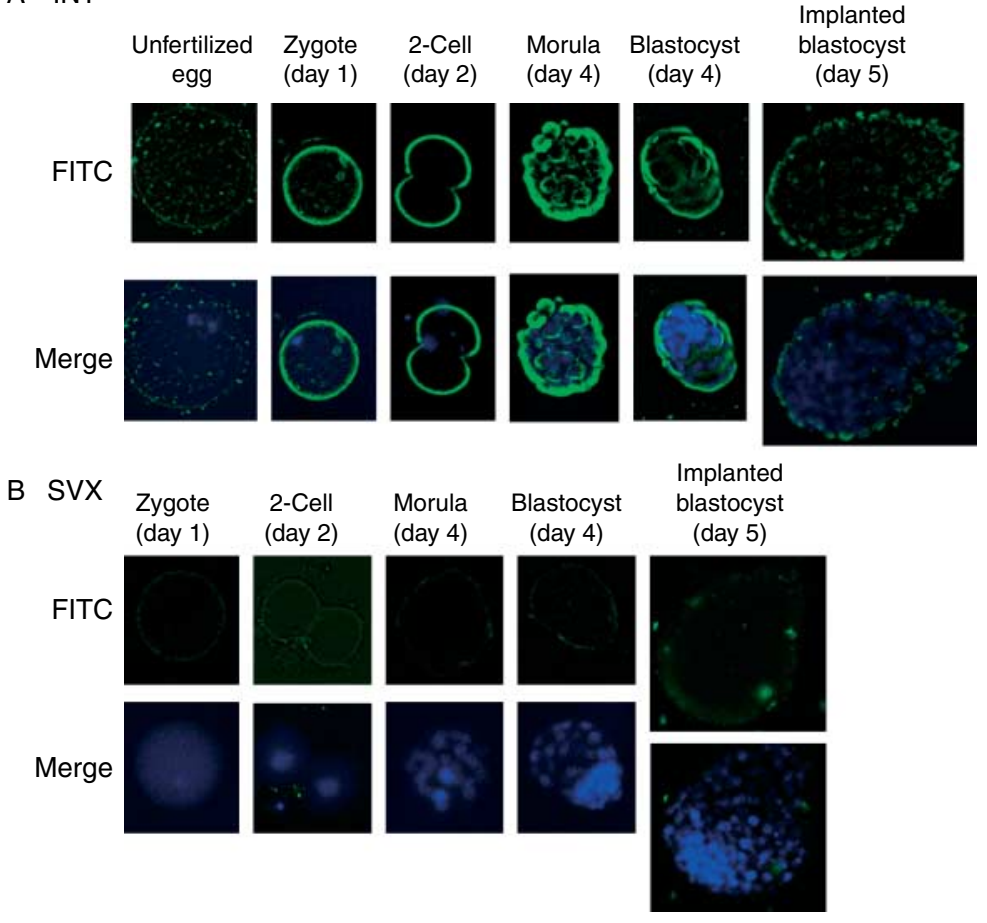

Figure 4 Expression of a2V in preimplantation embryos. Photomicrograph shows immunolocalization of a2V in different stages of preimplantation embryos recovered from females mated with intact or SVX mating. FITC-stained with anti-a2 $\mathrm{V}$ antibodies (green) and DAPI nuclear stain (blue). Data are representative of four experiments.

Our previous studies showed that the key portion of the a2 $\mathrm{V}$ protein is a2NTD, the N-terminal portion that is released from the activated monocyte and induces the cytokines secretion (Kwong et al. 2011). In this study, we showed that capacitated sperm secrete a2NTD in the surrounding milieu. To confirm whether a2NTD stimulates cytokine secretion in the female uterus, we injected a2NTD intrauterine into the prepared uterine horn (proestrous stages uterus). a2NTD induced the expression of different cytokine expression such as Lif, $I / 1 \mathrm{~b}, \mathrm{Tnf}$, and $\mathrm{Ccl} 2$ in the injected uterine horn. Thus, we suggest that following capacitation of the sperm in the proestrous stage uterus, sperm initiates inflammation in the uterine horn by the release of the immune regulatory molecule a2NTD, which in turn induces the expression of inflammatory cytokines.

Capacitation has been well studied and involves a cascade of biochemical and physiological changes including changes in metabolism and sperm motility, actin polarization, and complex signal transduction (Breitbart 2003). However, little is known about the protein translation that occurs during capacitation. The mature sperm has a reservoir of a complex population mRNA, which aid in the replacement of degraded proteins and which are critical for postfertilization events (Ostermeier et al. 2002, 2004, 2005). Ejaculated sperm are capable of using mRNA transcripts for protein translation during capacitation in the female reproductive tract (Miller \& Ostermeier 2006). In the capacitationdependent process, nuclear-encoded mRNA can be translated by the mitochondrial type ribosomes whereas cytoplasmic machinery is not involved. In a recent viewpoint, mature sperm has a capacity of de novo protein translation (Gur \& Breitbart 2008).

Recent reports suggested that sperm deliver not only the male genome to the ova but also several crucial molecules such as RNA and proteins required for the fertilization and early embryonic development (Ostermeier et al. 2002, 2004, 2005, Ainsworth 2005). We detected the presence of both crucial immune regulatory molecules a2 $\mathrm{V}$ and Lif in the capacitated sperm. After fertilization in INT mating, the expression of $\mathrm{a} 2 \mathrm{~V}$ is remarkably greater in the zygote than in the unfertilized egg. These data show that a high level of a2V expression is maintained in the developing preimplantation embryos recovered from intact mating until the time of implantation. Moreover, we showed that developing blastocysts express both a2V and Lif. These molecules are known to play a vital role in the establishment of successful implantation. Gene knockouts of Lif and LIF antagonist studies on mice have shown that deleting the $L i f$ receptor gene or impeding the interaction of Lif with the receptor results in implantation failure (Stewart et al. 1992). However after implantation, neither a $2 v$ nor Lif expression was detected in the implanting blastocyst. In contrast to SVX mating, the preimplantation stage embryo had lower expression of a2V. Together, these results indicate that in INT mating, the active immune response is established as shown by the presence of a2 $\mathrm{V}$ and LIF before embryo implantation and then ceased after implantation. In contrast to SVX mating, lower a2V expression indicates the importance of seminal plasma 

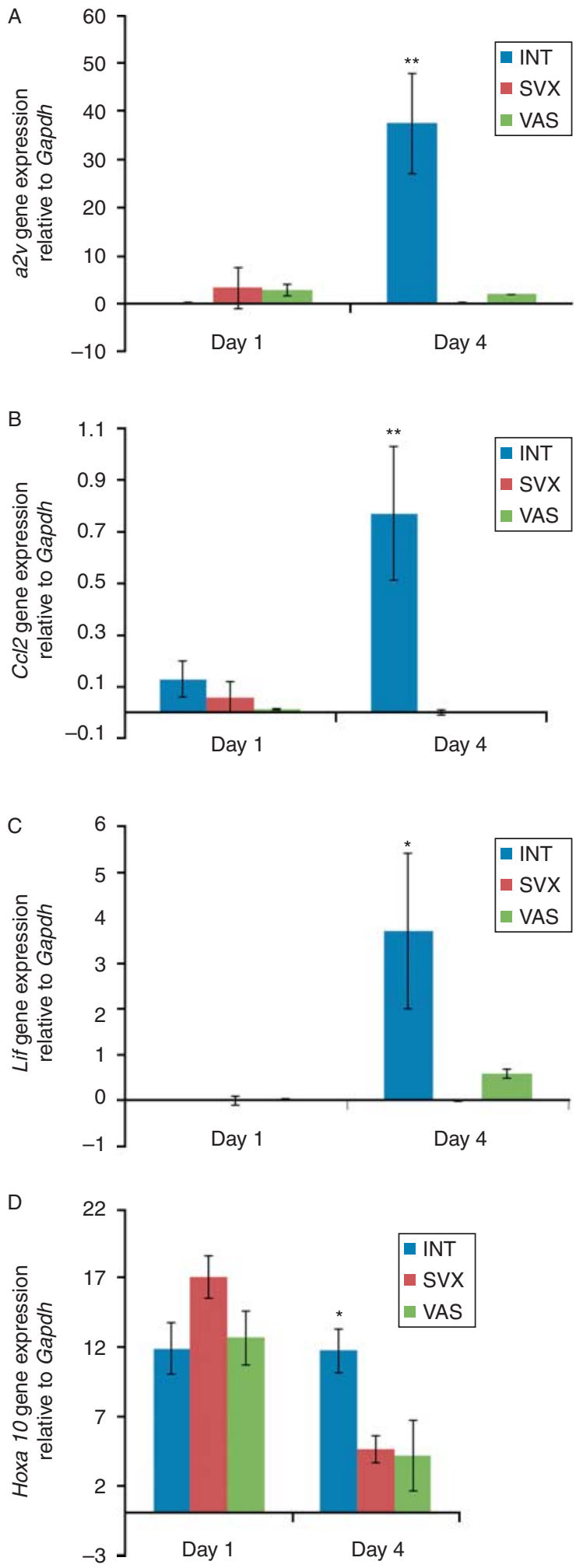

Figure 5 Gene expression of a2v, CCl2, Lif, and Hoxa10 in the uterus. The bar diagrams shows the gene expression of (A) a2 V, (B) CCl2 (C) Lif, and (D) Hoxa10 in the uterine horn recovered from females mated with INT, SVX, or VAS males. Data are from four independent experiments (mean \pm S.E.M.). **Significant difference between groups, $P<0.01$. *Significant difference between groups, $P<0.05$. as a key regulator that influences the local immune environment during pregnancy.

The remarkable finding of this study was the infiltration of macrophage subsets to the uterus during the preimplantation period. Our data suggests that during the preimplantation period, the microenvironment of female uterus becomes inflammatory in INT mating. It has been previously reported that within the hour of natural insemination, the surge of proinflammatory cytokines induces the infiltration of inflammatory leukocytes including macrophages, dendritic cells, and granulocytes into the female uterus. This response is short-lived and is resolved near the window of implantation with the decline of proinflammatory cytokines and chemokines (Robertson et al. 1992, 1996). Our data quantifying uterine $M 1$ and $M 2$ macrophages and their polarization ratios clearly show that within a few hours of insemination, on day 1 of pregnancy, the number of macrophages migrating into the uterus increased until the window of implantation on day 4 . These macrophages were mainly skewed to $M 1$ macrophages as the ratios ranged from 1.6 to 1.45 in the INT mating. However, in SVX or VAS matings, the infiltration of M1 and M2 macrophages was lower during the preimplantation period of pregnancy. Moreover, the polarization pattern was mainly skewed to M2 phenotypes on day 4 of pregnancy in the SVX mating. These data also indicate that the dynamic infiltration of $\mathrm{M} 1$ and M2 macrophages was corresponded with higher expression of uterine a2V through the induction of CCl2 expression. Cumulatively, these results provide evidence that the presence of the early inflammatory phase of pregnancy may be a reflective event of upregulation of a2 $\mathrm{V}$ and $\mathrm{Ccl} 2$ in the uterus recovered from the INT mating where the uterus gets exposed to seminal plasma as well as sperm for successful pregnancy outcome.

It is intriguing that control of the immune response thought to be vital in the mother to maintain pregnancy may develop actively by the male. It has been previously reported that male semen contributes to the events through which maternal tolerance is established at the outset of pregnancy (Manjunath et al. 1994, Robertson et al. 2009). We have previously shown that the a2V expression was significantly higher in the preimplantation embryos and placentas of nonabortion-prone $\left(\$ B A L B / C \times{ }^{\top} \mathrm{BALB} / \mathrm{C}\right.$ and $\left.\% \mathrm{CBA} \times{ }^{\top} \mathrm{BALB} / \mathrm{C}\right)$ matings compared with the abortion-prone ( $\left.q \mathrm{CBA} \times{ }^{\top} \mathrm{DBA}\right)$ matings. The a2 $\mathrm{V}$ expression in preimplantation embryos and placenta was significantly higher when BALB/C males were used than when DBA male were used. This highlights the importance of the male contribution to the amount of a2 V. It can be postulated that a low paternal contribution of a2V may be responsible for the severe pregnancy complications observed in mothers from recurrent miscarriage (Jaiswal et al. 2011). In this study, we showed that lower a2V expression in both 

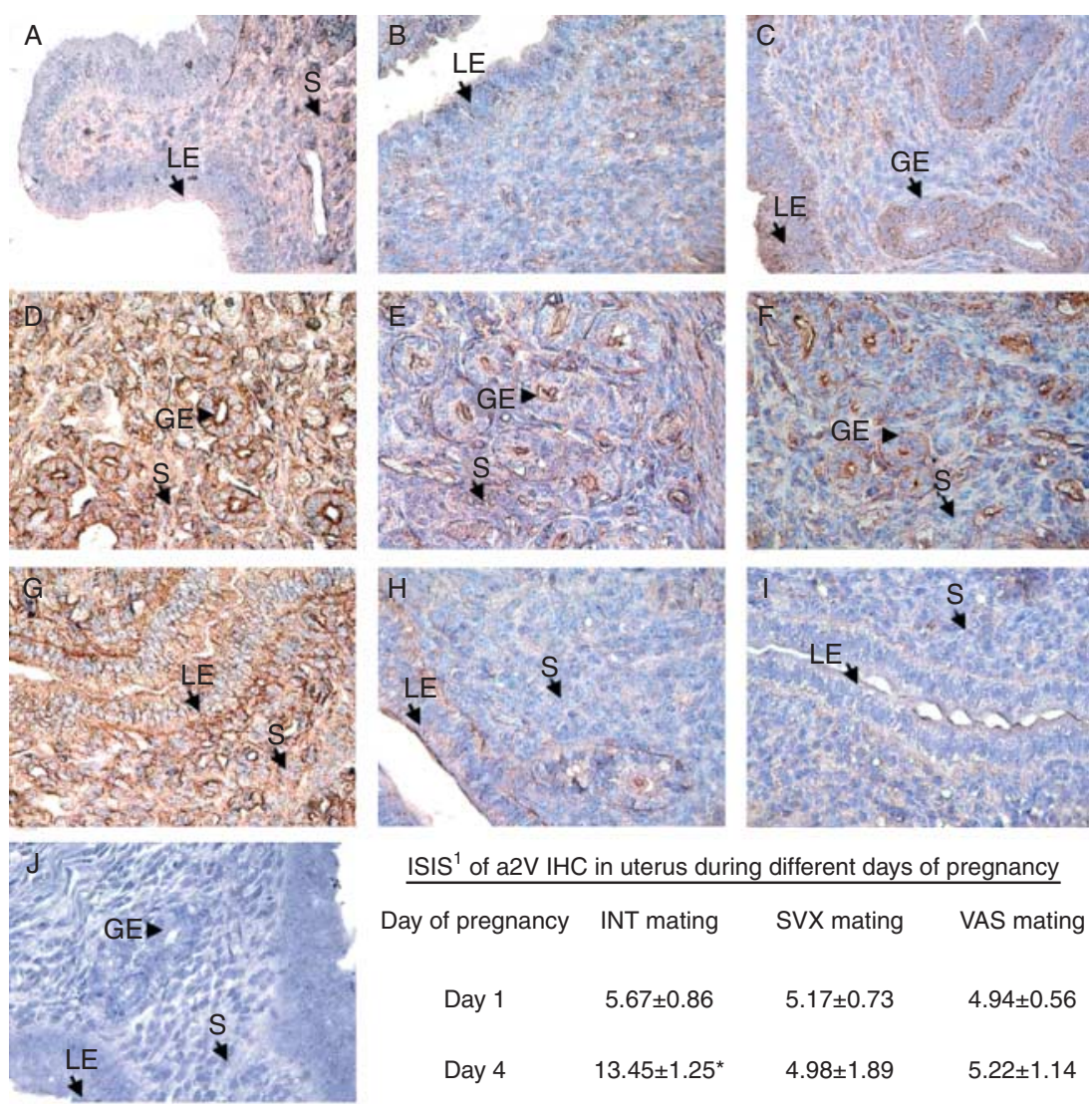

$\underline{I_{S I S}{ }^{1} \text { of a2V IHC in uterus during different days of pregnancy }}$

Day of pregnancy INT mating

SVX mating

VAS mating

Day 1

$5.67 \pm 0.86$

$5.17 \pm 0.73$

$4.94 \pm 0.56$

Day 4

$13.45 \pm 1.25^{*}$

$4.98 \pm 1.89$

$5.22 \pm 1.14$
Figure 6 Distribution of a2 $\mathrm{V}$ protein in the mouse uterus on different days of pregnancy. The brown staining indicates that a2 $\mathrm{V}$ protein localization in the uterine horn recovered from females mated with INT, SVX, or VAS males. (A) Day 1, INT mating; (B) day 1, SVX mating; (C) day 1, VAS mating; (D and $\mathrm{G})$ day 4, INT mating; $(\mathrm{E}$ and $\mathrm{H})$ day 4, SVX mating; ( $F$ and I) day 4, VAS mating; (J) negative control ( $n=4$ for each group). GE, glandular epithelium; LE, luminal epithelium; $S$, stroma; $(40 \times)$. Data are representative of four experiments. Data shown in the table is expressed in mean \pm S.E.M. ${ }^{1}$ Immunostaining index score $(\mathrm{ISIS})=$ stained area score $(\mathrm{SAS}) \times$ immunostaining intensity score (IIS). *Significant difference between groups, $P<0.05$. preimplantation embryos and uterus was directly associated with the reduced fertility rate in the SVX mating. No live fetuses were observed in the uteri recovered from females mated with SVX-deficient males (data not shown). These data are in agreement with the previous reports that removal of the seminal vesicle reduces the fertility rate in the mouse (Peitz \& Olds-Clarke 1986).

In summary, this study provides new insights into the role of capacitation in facilitating pregnancy through the regulation of immune process, which is characterized by the expression of a2 $\mathrm{V}$ and inflammatory cytokines in capacitated sperm. Given the critical role that the release of a2 $\mathrm{V}$ subcomponent a2NTD from the capacitated sperm and its involvement in the expression of inflammatory cytokines, there is strong evidence that it is an essential molecule for onset of pregnancy. Following fertilization of the ova, the embryo at the maternal interface takes over the regulation of the local immune response by expressing $\mathrm{a} 2 \mathrm{~V}$. In the postmating period, the inflammatory phase was confirmed by the recruitment of M1 macrophages in the early pregnant uterus, which is the reflective event of the upregulation a2 $\mathrm{V}$ and $\mathrm{Ccl} 2$ expression. This study also provides evidence that the exposure of both sperm and seminal plasma is crucial for facilitating pregnancy through upregulation of a2 $\mathrm{V}$ and panel of genes that confers uterine receptivity near the window of implantation.

\section{Materials and Methods \\ Mice and surgical treatments}

Inbred strains of BALB/C $\left(\mathrm{H}-2^{\mathrm{d}}\right)$ mice (6-7 week, 18-20 g) were used for this study (Jackson Laboratories, Bar Habor, ME, USA). The housing and handling of experimental animals were in accordance with the guidelines of Institutional Animal Care and Use Committee.

Seminal plasma-deficient (SVX) and VAS BALB/c males were prepared as described by Robertson et al. (1996) with slight modifications. Male mice were anesthetized by the i.p. dose of ketamine $(100 \mathrm{mg} / \mathrm{kg}$ body weight) and xylazine $(16 \mathrm{mg} / \mathrm{body}$ weight). Male mice were VAS by bilateral ligation of the vas deferens, about $4-5 \mathrm{~mm}$ apart and cut out a section of vas deferens from in between the knots through a transverse incision at the abdominal wall. For SVX males, seminal vesicles were removed through a transverse incision in the abdominal wall after ligation and serving of the proximal tubule at the base of the gland. The body wall was sutured and skin was closed up using two clips to hold the wound closed. The surgical males were allowed to recover for at least 10 days before mating. VAS males were proven incapable of fertilization by examination of females 8 days after mating. For experimental matings, females were individually caged with intact (INT) SVX and VAS stud 

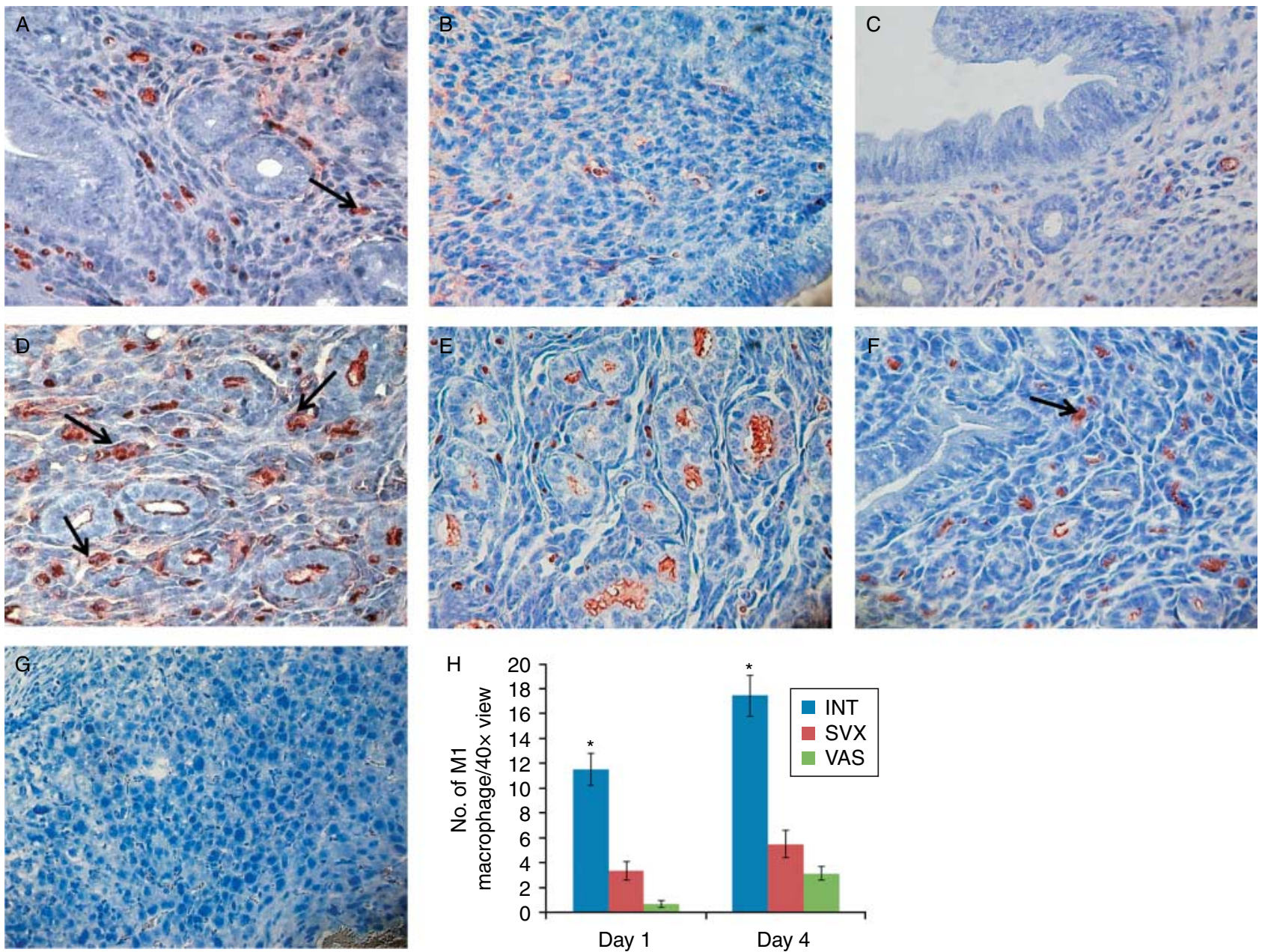

Figure 7 Infiltration of M1 macrophages in the uterus. Distribution of M1 macrophages (black arrow) in mouse uterus recovered from females mated with INT, SVX, or VAS males. (A) Day 1, INT mating; (B) day 1, SVX mating; (C) day 1, VAS mating; (D) day 4, INT mating; (E) day 4, SVX mating; (F) day 4, VAS mating; (G) negative control for staining of M1 and M2 macrophages ( $n=4$ for each group) ( $40 \times$ ). Panel $\mathrm{H}$ shows the quantification of M1 macrophages in the uterus recovered from intact, SVX, or VAS mating on days 1 and 4 of pregnancy. Data are representative of four experiments (A, B, C, D, E, F and G) or are four independent experiments (H; mean \pm s.E.M.). *Significant difference between groups, $P<0.05$.

males. Females mated with INT males (intact or INT mating) and VAS males (VAS mating) were checked for the presence of vaginal plug for the confirmation of mating. Mating with SVX males (SVX mating) was detected by the presence of sperm in the vaginal smear prepared on every morning. The confirmation of mating was considered as day 1 of pregnancy.

\section{Recovery of embryos and uterine horn}

Embryos were recovered from pregnant females mated with INT or SVX. The females were selected for the retrieval of zygotes between 12 and $13 \mathrm{~h}$ on the day of the appearance of vaginal plugs, i.e. day $1, \sim 14 \mathrm{hpc}$ from oviduct in a sterile petridish with sterile PBS. The two-cell embryos were recovered between 14 and $15 \mathrm{~h}$ the following the day of the appearance of vaginal plugs, i.e. day $2, \sim 40 \mathrm{hpc}$ from oviduct. The compact morula and blastocysts were recovered on day 4 , 84-90 hpc from uterus respectively. These preimplantation embryos were used for further studies. The uterine horns were recovered from pregnant females mated with INT, SVX, or VAS males on days 1 ( $\sim 14 \mathrm{hpc}$ ) and 4 ( $\sim 90 \mathrm{hpc})$ of pregnancy and used for further studies.

\section{Localization of a2 $\mathrm{V}$ in sperm and different preimplantation stages embryos}

Sperm were collected from epididymis of 8 week BALB/c males and incubated with Krebs-Ringer (KR) buffer (Sigma Chemicals Co.) with or without calcium and BSA for 90 min at $37{ }^{\circ} \mathrm{C}$ in $5 \%$ $\mathrm{CO}_{2}$. KR buffer contains $\mathrm{HCO}_{3}^{-}$and induces the capacitation of sperm in the presence of calcium and BSA (named as capacitation buffer). After incubation with these buffers, sperm were fixed with $4 \%$ paraformaldehyde, permeabilized with $0.1 \%$ Triton X-100 and 3\% BSA, and placed in a 1:100 dilution $(20 \mu \mathrm{g} / \mathrm{ml})$ of a mouse MAB to a2 $\mathrm{V}$ (named as $2 \mathrm{C} 1$ ) in $1 \%$ BSA in PBS (BSA-PBS) overnight at $4{ }^{\circ} \mathrm{C}$. After washing with BSA-PBS, the specimens were incubated with secondary antibody, FITC rabbit polyclonal antimouse IgG (Dako) at a 1:20 dilution in BSA-PBS for $45 \mathrm{~min}$ at room temperature. To visualize the nuclei, the sperm were counterstained with 

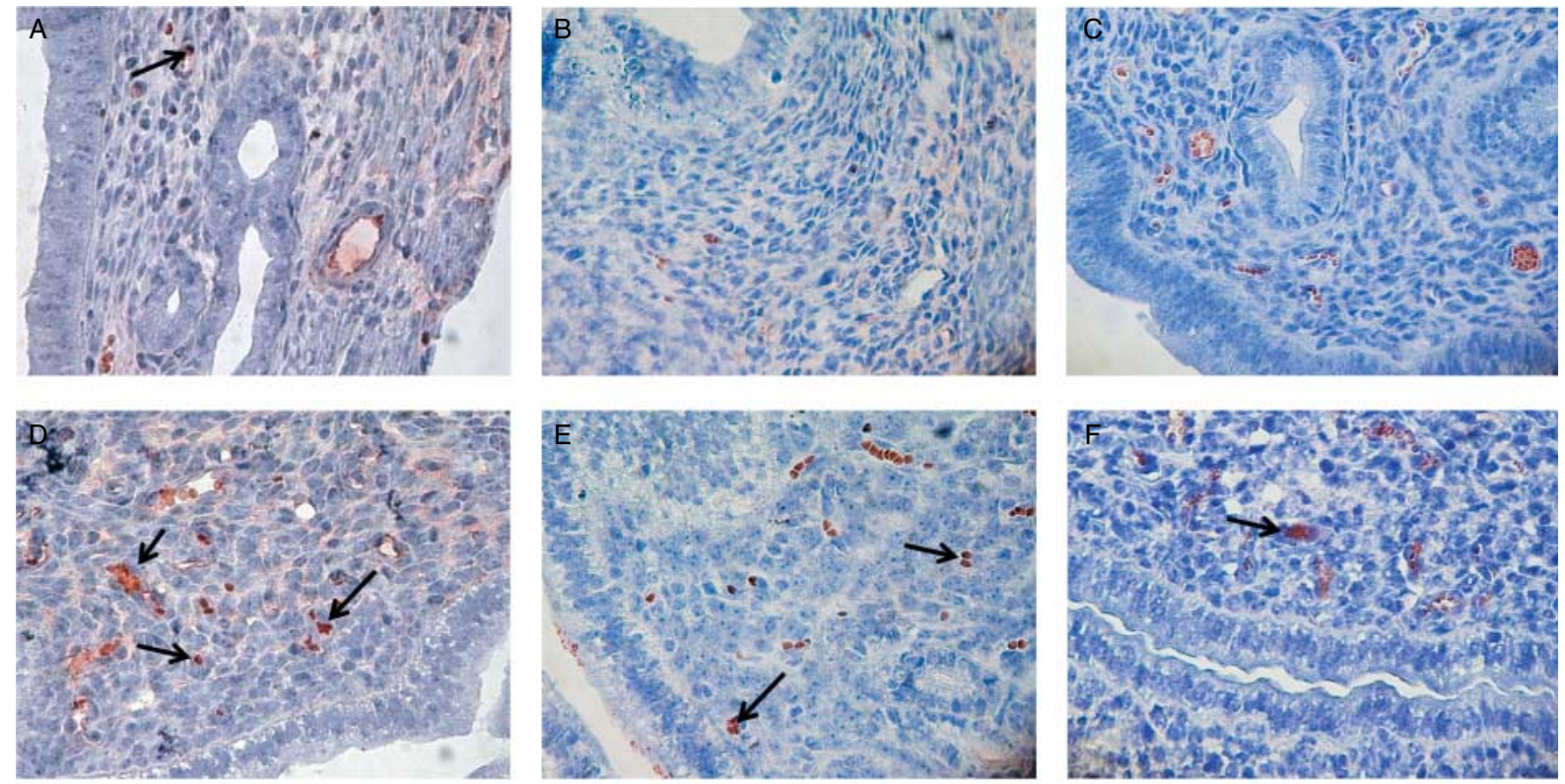

G

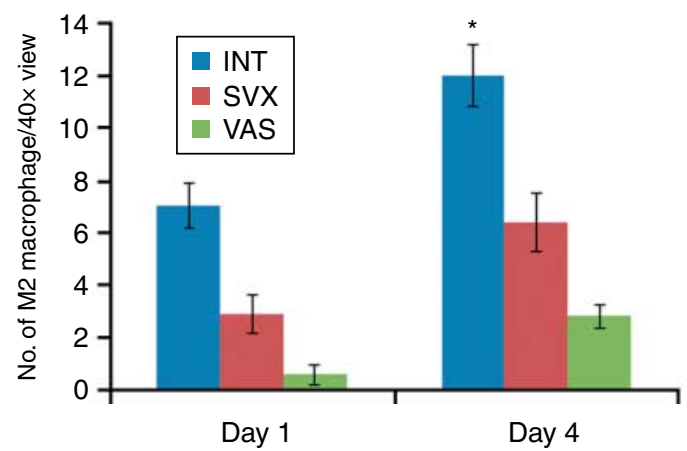

$\mathrm{H}$
M1/M2 polarization

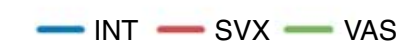

1.6

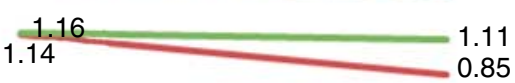

Figure 8 Infiltration of M2 macrophages in the uterus. Distribution of M2 macrophages (black arrow) in mouse uterus recovered from females mated with INT, SVX, or VAS mating mating. (A) Day 1, INT mating; (B) day 1, SVX mating; (C) day 1, VAS mating; (D) day 4, INT mating; (E) day 4, SVX mating; (F) day 4, VAS mating ( $n=4$ for each group) $(40 \times)$. Panel $\mathrm{G}$ shows the quantification of M2 macrophages receptively in the uterus recovered from intact, SVX, or VAS mating on days 1 and 4 of pregnancy. Panel $\mathrm{H}$ shows the polarization of M1 and M2 macrophages in the uterus. Data are representative of four experiments (A, B, C, D, E and F) or of four independent experiments ( $\mathrm{G}$ and $\mathrm{H}$; mean \pm s.E.M.). *Significant difference between groups, $P<0.05$.

4',6-diamidino-phenylinode (DAPI; $0.5 \mu \mathrm{g} / \mathrm{ml}$ ). After mounting the specimens on slides with vectashield, antigen distribution was examined under a Nikon eclipse TE2000-S florescence microscope (Nikon Instrument, Inc., Melville, NY, USA). One group of sperm was directly used for a2V immune-staining as described earlier without any incubation with KR buffers. Experiment was repeated five times (number of animals used $=10)$. Embryos at different stages of preimplantation were collected from females mated with INT and SVX males and stained for immunolocalization of a2 $\mathrm{V}$ as described earlier for sperm. The number of animals was three for each day of pregnancy studied. Experiments were repeated four times.

\section{Gene expression of a2v and different cytokines in sperm}

Sperm were collected and incubated as described earlier. Sperm were washed three times and resuspended in $50 \mu \mathrm{l}$ sterile PBS and used for extraction of total cellular RNA using High Pure RNA Isolation Kit (Roche Diagnostics $\mathrm{GmbH}$ ) according to the manufacturer's instructions. RNA samples were stored at $-80^{\circ} \mathrm{C}$ until further use. The cDNA was generated from total cellular RNA by RT at $50{ }^{\circ} \mathrm{C}$ for $60 \mathrm{~min}$ using random hexamer primer of transcriptor first-strand cDNA synthesis kit (Roche Diagnostics GmBH). Multiplex realtime PCR was performed by TaqMan gene analysis using the Applied Biosystems StepOne Real-time PCR system for a2v, and different cytokines Lif, $/ / 1 \mathrm{~b}$, Tnf, and $\| 10$ were measured and normalized to the Gapdh housekeeping gene. Real-time PCR was performed using universal PCR master mix reagent (Applied Biosystems, Foster City, CA, USA) according to the manufacturer's instructions. The prevalidated TaqMan gene expression assays for Atp6v0a2 (Mm00441848_m1), I/1b (Mm00434228_m1), Tnf (Mm00443258_m1), Lif (Mm00434 761_m1), CCl2 (Mm00441242_m1), I/10 (Mm00439614_m1), 
and Gapdh (part number 4352339E) were purchased from Applied Biosystems. Experiments were repeated five times (number of animals used $=5$ ).

\section{Gene expression of a2v and Lif in different preimplantation stage embryos and uterus}

\section{Embryo}

The gene expression of $a 2 v$ and Lif in the different stage preimplantation embryos was analyzed by TaqMan gene expression Cell-to-Ct kit according to the manufacture's protocol with slight modifications. A total of 25 embryos were collected at each stage, washed, and resuspended in $10 \mu \mathrm{l}$ sterile PBS and used to prepare cell lysates for RT-PCR. Multiplex real-time PCR was performed for $a 2 v$ and Lif and normalized to the Gapdh housekeeping gene. The prevalidated TaqMan gene expression assays were used as mentioned earlier. The number of animals was four for each day of pregnancy studied. Experiments were repeated three times.

\section{Uterus}

Total cellular RNA was extracted by Melt Total nucleic acid isolation system (Ambion, Austin, TX, USA) according to the manufacturer's protocol. Quantity and integrity of RNA were confirmed by the ratio at 260:280 nm and electrophoresis was performed on $1.5 \%$ native agarose gel to visualize $18 S$ and $28 S$ rRNA subunits. Samples were stored at $-80{ }^{\circ} \mathrm{C}$ until further use. The cDNA was generated from $1 \mu \mathrm{g}$ total cellular RNA by RT at $50{ }^{\circ} \mathrm{C}$ for $60 \mathrm{~min}$ using random hexamer primer of transcriptor first-strand cDNA synthesis kit (Roche Diagnostics $\mathrm{GmBH})$. Multiplex real-time PCR was performed for a2v, Lif, CCl2, and Hoxa10 as mentioned earlier. The prevalidated TaqMan gene expression assays were used as mentioned earlier. Experiments were repeated four times.

\section{Immunohistochemistry}

The uterine horns were collected from females mated with INT, SVX, or VAS males on days 1 and 4 of pregnancy. These uterine horns were used for the immunostaining of a2 $\mathrm{V}$ and different macrophage phenotypes (M1 and M2 macrophages). The uterine horns were fixed in $4 \%$ paraformaldehyde in PBS at $4{ }^{\circ} \mathrm{C}$ overnight. Tissue was rinsed three times in PBS for $5 \mathrm{~min}$ with rocking and infused with $30 \%$ sucrose solution at $4{ }^{\circ} \mathrm{C}$ overnight or till the tissue was sunk. The tissues were snap frozen in the OCT (Tissue-Tek, Torrance, CA, USA) by liquid nitrogen. Frozen tissue was stored at $-80{ }^{\circ} \mathrm{C}$ until further use. Frozen $5 \mu \mathrm{m}$ sections from frozen tissues were mounted onto saline-coated glass slides (Dako, Carpinteria, CA, USA) and stored at $-80{ }^{\circ} \mathrm{C}$ until used. The Dako EnVision + System-HRP (DAB) (Dako) was used to stain the frozen sections according to the manufacturer's instructions with slight modification. For primary antibody reaction, sections were incubated in a $1: 100$ dilution $(20 \mu \mathrm{g} / \mathrm{ml})$ of mouse $\mathrm{MAB}$ to $\mathrm{a} 2 \mathrm{~V}$ in $1 \% \mathrm{BSA}-$ PBS for $1 \mathrm{~h}$. After washing, sections were incubated with secondary antibody-labeled polymer HRP antimouse IgG1. The $3,3^{\prime}$-diaminobenzidine chromogen was used as substrate for the EnVision + HRP system according to the manufacturer's instructions. A mouse IgG1 isotype control (Abcam, Cambridge, MA, USA) was used at the same concentration as the primary antibody. The sections were counterstained with Meyer's hematoxylin and mounted in faramount aqueous mounting medium (both from Dako). The immune staining of a2 $\mathrm{V}$ was evaluated in the image generated by light microscopy (Carl Zeiss, Weesp, The Netherlands) and high-resolution camera (Canon G10, Japan). The tissue immunostaining results were scored negative if no immunopositive tissue was present. The total score was based on the percentage of stained tissue and immunostaining intensity. The percentage of stained tissue and immunostaining intensity was calculated according to the method described in Teixeira Gomes et al. (2009). Then, immunostaining index score (ISIS) was generated by the equation stained area score (SAS) multiplied by the immunostaining intensity score (IIS): (ISIS =SAS $\times$ IIS).

We used antibodies targeted to ITGAX and MCR1 for M1 and M2 subtypes respectively (Aron-Wisnewsky et al. 2009, Fujisaka et al. 2009, Jaiswal et al. 2011). The Dako EnVision+ System HRP (AEC) (Dako) was used to stain the frozen sections according to the manufacturer's instructions with slight modification. 1:100 and 1:25 dilutions were used for ITGAX and MCR1 (Abcam) receptively. The number of macrophages was counted in at least ten randomly chosen areas per uterine section at $40 \times$ view. The number of animals was four for each group. Six sections were analyzed per animal.

\section{I.u. injection of a2NTD}

BALB/C females were injected i.p. with $5 \mathrm{IU}$ pregnant mare serum gonadotropin (PMSG; Folligon, Sigma) and human chorionic gonadotropin (hCG; Chorulon, Intervet, Boxmeer, Holland). After $5 \mathrm{~h}$ of hCG injection, a single dose of $10 \mathrm{ng}$ a2NTD in $15 \mu \mathrm{l}$ sterile PBS was injected in one of the uterine horns. The control received $15 \mu$ sterile PBS by the same route. Uterine horns were recovered after $24 \mathrm{~h}$ of injection and stored at $-80{ }^{\circ} \mathrm{C}$ until use. Total cellular RNA was extracted by Melt Total nucleic acid isolation system (Ambion) according to the manufacturer's protocol. The cDNA was generated from $1 \mu \mathrm{g}$ total cellular RNA by $\mathrm{RT}$ at $50{ }^{\circ} \mathrm{C}$ for $60 \mathrm{~min}$ using random hexamer primer of transcriptor first-strand cDNA synthesis kit (Roche Diagnostics GmBH). The multiplex real-time PCR was performed for different cytokines Lif, I/1 b, Tnf, Ccl2, and I/10 as mentioned earlier. Experiments were repeated three times. The numbers of animals were four for each group.

\section{Statistical analyses}

The results of each experiment were analyzed by one-way ANOVA with Duncan's multiple range test for comparison of the significance level $(P)$ between groups. A $P<0.05$ value was considered as a significant difference between the values compared.

\section{Supplementary data}

This is linked to the online version of the paper at http://dx.doi. org/10.1530/REP-12-0036. 


\section{Declaration of interest}

The authors declare that there is no conflict of interest that could be perceived as prejudicing the impartiality of the research reported.

\section{Funding}

This research did not receive any specific grant from any funding agency in the public, commercial or not-for-profit sector.

\section{Acknowledgements}

The authors thank the Clinical Laboratory, Rosalind Franklin University of Medical and Science, North Chicago, IL for the grant support.

\section{References}

Aghajanova L 2010 Update on the role of leukemia inhibitory factor in assisted reproduction. Current Opinion in Obstetrics \& Gynecology 22 213-219. (doi:10.1097/GCO.0b013e32833848e5)

Ainsworth C 2005 Cell biology: the secret life of sperm. Nature $\mathbf{4 3 6}$ 770-771. (doi:10.1038/436770a)

Aron-Wisnewsky J, Tordjman J, Poitou C, Darakhshan F, Hugol D, Basdevant A, Aissat A, Guerre-Millo M \& Clement K 2009 Human adipose tissue macrophages: $\mathrm{m} 1$ and $\mathrm{m} 2$ cell surface markers in subcutaneous and omental depots and after weight loss. Journal of Clinical Endocrinology and Metabolism 94 4619-4623. (doi:10.1210/jc. 2009-0925)

Aumuller G \& Riva A 1992 Morphology and functions of the human seminal vesicle. Andrologia 24 183-196. (doi:10.1111/j.1439-0272.1992. tb02636.x)

Austin CR 1951 Observations on the penetration of the sperm in the mammalian egg. Australian Journal of Scientific Research, Series B: Biological Sciences 4 581-596.

Breitbart H 2003 Signaling pathways in sperm capacitation and acrosome reaction. Cellular and Molecular Biology 49 321-327.

Chang MC 1951 Fertilizing capacity of spermatozoa deposited into the fallopian tubes. Nature 168 697-698. (doi:10.1038/168697b0)

Chaouat G, Dubanchet S \& Ledee N 2007 Cytokines: important for implantation? Journal of Assisted Reproduction and Genetics 24 491-505. (doi:10.1007/s10815-007-9142-9)

Chaouat G, Petitbarat M, Dubanchet S, Rahmati M \& Ledee N 2010 Tolerance to the foetal allograft? American Journal of Reproductive Immunology 63 624-636. (doi:10.1111/j.1600-0897.2010.00832.x)

Critchley HO, Kelly RW, Lea RG, Drudy TA, Jones RL \& Baird DT 1996 Sex steroid regulation of leukocyte traffic in human decidua. Human Reproduction 11 2257-2262.

Fujisaka S, Usui I, Bukhari A, Ikutani M, Oya T, Kanatani Y, Tsuneyama K, Nagai Y, Takatsu K, Urakaze M et al. 2009 Regulatory mechanisms for adipose tissue $M 1$ and $M 2$ macrophages in diet-induced obese mice. Diabetes 58 2574-2582. (doi:10.2337/db08-1475)

Gomez-Lopez N, Guilbert LJ \& Olson DM 2010 Invasion of the leukocytes into the fetal-maternal interface during pregnancy. Journal of Leukocyte Biology 88 625-633. (doi:10.1189/jlb.1209796)

Gordon S 2003 Alternative activation of macrophages. Nature Reviews. Immunology 3 23-35. (doi:10.1038/nri978)

Gur Y \& Breitbart H 2008 Protein synthesis in sperm: dialog between mitochondria and cytoplasm. Molecular and Cellular Endocrinology 282 45-55. (doi:10.1016/j.mce.2007.11.015)

Hunt JS \& Pollard JW 1992 Macrophages in the uterus and placenta. Current Topics in Microbiology and Immunology 181 39-63.

Hunt JS, Manning LS, Mitchell D, Selanders JR \& Wood GW 1985 Localization and characterization of macrophages in murine uterus. Journal of Leukocyte Biology 38 255-265.
Hunt JS, Petroff MG \& Burnett TG 2000 Uterine leukocytes: key players in pregnancy. Seminars in Cell \& Developmental Biology 11 127-137. (doi:10.1006/scdb.2000.0158)

Jaiswal MK, Gilman-Sachs A, Chaouat G \& Beaman KD 2011 Placental ATPase expression is a link between multiple causes of spontaneous abortion in mice. Biology of Reproduction 85 626-634. (doi:10.1095/ biolreprod.111.092494)

Jones RL, Kelly RW \& Critchley HO 1997 Chemokine and cyclooxygenase-2 expression in human endometrium coincides with leukocyte accumulation. Human Reproduction 12 1300-1306. (doi:10.1093/ humrep/12.6.1300)

Krumlauf R 1994 Hox genes in vertebrate development. Cell 78 191-201. (doi:10.1016/0092-8674(94)90290-9)

Kwong C, Gilman-Sachs A \& Beaman K 2011 Tumor-associated a2 vacuolar ATPase acts as a key mediator of cancer-related inflammation by inducing pro-tumorigenic properties in monocytes. Journal of Immunology 186 1781-1789. (doi:10.4049/jimmunol.1002998)

Lee GW, Boomer JS, Gilman-Sachs A, Chedid A, Gudelj L, Rukavina D \& Beaman KD 2001 Regeneration and tolerance factor of the human placenta induces IL-10 production. European Journal of Immunology 31 687-691. (doi:10.1002/1521-4141(200103)31:3 <687::AID-IMMU687 $>3.0 . \mathrm{CO} ; 2-1)$

Maegawa M, Kamada M, Irahara M, Yamamoto S, Yoshikawa S, Kasai Y, Ohmoto Y, Gima H, Thaler CJ \& Aono T 2002 A repertoire of cytokines in human seminal plasma. Journal of Reproductive Immunology $\mathbf{5 4}$ 33-42. (doi:10.1016/S0165-0378(01)00063-8)

Manjunath P, Chandonnet L, Leblond E \& Desnoyers L 1994 Major proteins of bovine seminal vesicles bind to spermatozoa. Biology of Reproduction 50 27-37. (doi:10.1095/biolreprod50.1.27)

Mantovani A, Sozzani S, Locati M, Allavena P \& Sica A 2002 Macrophage polarization: tumor-associated macrophages as a paradigm for polarized M2 mononuclear phagocytes. Trends in Immunology 23 549-555. (doi:10.1016/S1471-4906(02)02302-5)

McGinnis W \& Krumlauf R 1992 Homeobox genes and axial patterning. Cell 68 283-302. (doi:10.1016/0092-8674(92)90471-N)

Miller D \& Ostermeier GC 2006 Towards a better understanding of RNA carriage by ejaculate spermatozoa. Human Reproduction Update 12 757-767. (doi:10.1093/humupd/dml037)

Moffett-King A 2002 Natural killer cells and pregnancy. Nature Reviews. Immunology 2 656-663. (doi:10.1038/nri886)

Mor G \& Koga K 2008 Macrophages and pregnancy. Reproductive Sciences 15 435-436. (doi:10.1177/1933719108317253)

Mor G, Cardenas I, Abrahams V \& Guller S 2011 Inflammation and pregnancy: the role of the immune system at the implantation site. Annals of the New York Academy of Sciences 1221 80-87. (doi:10.1111/ j.1749-6632.2010.05938.x)

Mosser DM 2003 The many faces of macrophage activation. Journal of Leukocyte Biology 73 209-212. (doi:10.1189/jlb.0602325)

Ntrivalas E, Gilman-Sachs A, Kwak-Kim J \& Beaman K 2007 The $\mathrm{N}$-terminus domain of the a2 isoform of vacuolar ATPase can regulate interleukin-1 beta production from mononuclear cells in co-culture with JEG-3 choriocarcinoma cells. American Journal of Reproductive Immunology 57 201-209. (doi:10.1111/j.1600-0897.2006.00463.x)

Ntrivalas E, Levine R, Kwong C, Gilman-Sachs A \& Beaman K 2010 The a2 isoform of vacuolar ATPase is a modulator of implantation and fetomaternal immune tolerance in early pregnancy. Journal of Reproductive Immunology 85 106-111. (doi:10.1016/j.jri.2009.10.010)

Ostermeier GC, Dix DJ, Miller D, Khatri P \& Krawetz SA 2002 Spermatozoal RNA profiles of normal fertile men. Lancet $\mathbf{3 6 0}$ 772-777. (doi:10.1016/S0140-6736(02)09899-9)

Ostermeier GC, Miller D, Huntriss JD, Diamond MP \& Krawetz SA 2004 Reproductive biology: delivering spermatozoan RNA to the oocyte. Nature 429 154. (doi:10.1038/429154a)

Ostermeier GC, Goodrich RJ, Moldenhauer JS, Diamond MP \& Krawetz SA 2005 A suite of novel human spermatozoal RNAs. Journal of Andrology 26 70-74.

Peitz B \& Olds-Clarke P 1986 Effects of seminal vesicle removal on fertility and uterine sperm motility in the house mouse. Biology of Reproduction 35 608-617. (doi:10.1095/biolreprod35.3.608)

Robertson SA 2007 Seminal fluid signaling in the female reproductive tract: lessons from rodents and pigs. Journal of Animal Science 85 E36-E44. (doi:10.2527/jas.2006-578) 
Robertson SA, Mayrhofer G \& Seamark RF 1992 Uterine epithelial cells synthesize granulocyte-macrophage colony-stimulating factor and interleukin-6 in pregnant and nonpregnant mice. Biology of Reproduction 46 1069-1079. (doi:10.1095/biolreprod46.6.1069)

Robertson SA, Mau VJ, Tremellen KP \& Seamark RF 1996 Role of high molecular weight seminal vesicle proteins in eliciting the uterine inflammatory response to semen in mice. Journal of Reproduction and Fertility 107 265-277. (doi:10.1530/jrf.0.1070265)

Robertson SA, O'Leary S \& Armstrong DT 2006 Influence of semen on inflammatory modulators of embryo implantation. Society of Reproduction and Fertility Supplement 62 231-245.

Robertson SA, Guerin LR, Bromfield JJ, Branson KM, Ahlstrom AC \& Care AS 2009 Seminal fluid drives expansion of the CD4+CD25+T regulatory cell pool and induces tolerance to paternal alloantigens in mice. Biology of Reproduction 80 1036-1045. (doi:10.1095/biolreprod. 108.074658)

Salicioni AM, Platt MD, Wertheimer EV, Arcelay E, Allaire A, Sosnik J \& Visconti PE 2007 Signalling pathways involved in sperm capacitation. Society of Reproduction and Fertility Supplement 65 245-259.

Satokata I, Benson G \& Maas R 1995 Sexually dimorphic sterility phenotypes in Hoxa10-deficient mice. Nature 374 460-463. (doi:10.1038/374460a0)

Skinner MA, MacLaren LA \& Wildeman AG 1999 Stage-dependent redistribution of the V-ATPase during bovine implantation. Journal of Histochemistry and Cytochemistry 47 1247-1254. (doi:10.1177/ 002215549904701004)

Stewart CL, Kaspar P, Brunet LJ, Bhatt H, Gadi I, Kontgen F \& Abbondanzo SJ 1992 Blastocyst implantation depends on maternal expression of leukaemia inhibitory factor. Nature 359 76-79. (doi:10.1038/359076a0)
Sun-Wada G, Murata Y, Yamamoto A, Kanazawa H, Wada Y \& Futai M 2000 Acidic endomembrane organelles are required for mouse postimplantation development. Developmental Biology 228 315-325. (doi:10.1006/dbio.2000.9963)

Sun-Wada GH, Imai-Senga Y, Yamamoto A, Murata Y, Hirata T, Wada Y \& Futai M 2002 A proton pump ATPase with testis-specific E1-subunit isoform required for acrosome acidification. Journal of Biological Chemistry 277 18098-18105. (doi:10.1074/jbc.M111567200)

Tabiasco J, Rabot M, Aguerre-Girr M, El Costa H, Berrebi A, Parant $\mathrm{O}$, Laskarin G, Juretic K, Bensussan A, Rukavina D et al. 2006 Human decidual NK cells: unique phenotype and functional properties - a review. Placenta 27 (Suppl A) S34-S39. (doi:10.1016/j.placenta.2006. 01.009)

Taylor HS, Vanden Heuvel GB \& Igarashi PA 1997 A conserved Hox axis in the mouse and human female reproductive system: late establishment and persistent adult expression of the Hoxa cluster genes. Biology of Reproduction 57 1338-1345. (doi:10.1095/biolreprod57.6.1338)

Teixeira Gomes RC, Verna C, Nader HB, dos Santos Simoes R, Dreyfuss JL, Martins JR, Baracat EC, de Jesus Simoes M \& Soares JM Jr 2009 Concentration and distribution of hyaluronic acid in mouse uterus throughout the estrous cycle. Fertility and Sterility 92 785-792. (doi:10.1016/j.fertnstert.2008.07.005)

Visconti PE 2009 Understanding the molecular basis of sperm capacitation through kinase design. PNAS 106 667-668. (doi:10.1073/pnas. 0811895106)

Received 26 January 2012

First decision 24 February 2012

Accepted 19 March 2012 